\title{
STUDI ETNOFARMASI SUKU DONDO KECAMATAN DONDO KABUPATEN TOLITOLI SULAWESI TENGAH
}

\section{ETHNOMEDICINAL STUDY ON DONDO TRIBE OF DONDO SUBDISTRICT, TOLITOLI REGENCY, CENTRAL SULAWESI}

\author{
Moh. Fajrin ${ }^{1}$, Nurlina Ibrahim ${ }^{1}$, Arsa Wahyu Nugrahani ${ }^{1}$ \\ ${ }^{1}$ Jurusan Farmasi, Fakultas MIPA, Universitas Tadulako, Palu, Indonesia
}

Received 27 Juli 2015, Accepted 20 September 2015

\begin{abstract}
A B S T R A K
Penelitian ini bertujuan untuk melakukan inventarisasi, mengetahui cara penggunaan dan organ tumbuhan yang dimanfaatkan sebagai obat oleh suku Dondo Kecamatan Dondo Kabupaten Tolitoli Sulawesi Tengah. Penelitian ini menggunakan metode kualitatif dan teknik pengambilan sampel yakni snowball sampling, dengan wawancara open-ended interview pada 4 informan yang diperoleh menggunakan media kuesioner. Berdasarkan hasil penelitian diketahui sebanyak 56 spesies tumbuhan dan terbagi dalam 32 familia yang dimanfaatkan sebagai obat. Tumbuhan yang paling banyak digunakan yaitu dari familia Euphorbiaceae sebanyak $11 \%$. Organ tumbuhan yang digunakan antara lain daun, tangkai daun, batang, kulit batang, bunga, buah, biji, rimpang, umbi, dan herba. Organ tumbuhan yang banyak dimanfaatkan adalah daun yang persentase pemanfaatannya adalah $62 \%$. Masyarakat suku Dondo di Kecamatan Dondo Kabupaten Tolitoli menggunakan tumbuhan obat untuk mengobati penyakit, pemulihan, dan pemeliharaan kesehatan. Cara pengolahannya antara lain direbus, ditumbuk, disangrai, dibakar, diperas, diseduh. Cara penggunaannya antara lain diminum, dimakan, dikunyah, dihirup uapnya, dioles, ditempelkan/dikompreskan, dipakai mandi, diikatkan, diteteskan, dan digosok di tempat yang sakit.
\end{abstract}

Kata kunci : Etnofarmasi, Tumbuhan Obat, Suku Dondo

\section{A B S T R A C T}

This study aims to inventory and to record plants and their parts used as medicine by Dondo Tribe in Dondo Subdistrict, Tolitoli Regency, Central Sulawesi. This research is a descriptive study using qualitative methods and snowball sampling technique through open-ended interviews to 4 informants using questionnaire. The results showed that 56 plant species divided into 32 familia were used as medicine. The most widely used plant was from Euphorbiaceae family as much as $11 \%$. Parts of plant which were used included leaf, petiole, stem, bark, flower, fruit, seed, rhizomes, tuber, and herb. Part of plant widely used was the leaf with percentage of utilization as much as 62\%. The people of Dondo Tribe in Tolitoli District use the plants for treatment of illness, recovery, and maintenance of health. The methods of processing included decocting, mashing, roasting, burning, squeezing, and brewing the parts of the plant. The ways of using included drinking, eating, chewing, smearing, dropping, affixing/compressing, attaching, and rubbing the plant preparations on the sore spot as well as inhaling the fumes, and mixing it with water for bathing.

Keywords: Ethnopharmacy, Medicinal Plants, Dondo Tribe.

*Corresponding author : Moh. Fajrin, moh.fajrin@yahoo.com (ph: +62-852-5641-5115) 


\section{PENDAHULUAN}

Salah satu ciri budaya masyarakat di negara berkembang adalah masih dominan unsur-unsur tradisional dalam kehidupan sehari-hari. Keadaan ini didukung oleh keanekaragaman hayati yang terhimpun dalam berbagai tipe ekosistem yang pemanfaatannya telah mengalami sejarah panjang sebagai bagian dari kebudayaan. Tradisi pengobatan berbagai suku bangsa atau sekelompok masyarakat yang tinggal di pedalaman, masih menggunakan tumbuhan sebagai bahan obat. Persepsi mengenai konsep sakit, sehat, dan keragaman jenis tumbuhan yang digunakan sebagai obat tradisional terbentuk melalui suatu proses sosialisasi yang secara turuntemurun dipercaya dan diyakini kebenarannya (Sosrokusumo, 1989).

$$
\text { Indonesia yang memiliki }
$$

keanekaragaman hayati, tersimpan potensi tumbuhan berkhasiat obat yang belum terungkap dengan maksimal. Potensi tersebut sangat berperan dalam menjamin kesehatan dan kesejahteraan apabila dimanfaatkan dengan baik. Keanekaragaman tumbuhan menyimpan sejuta potensi untuk dimanfaatkan sebagai obat melalui cara pengolahan yang tepat. (Sosrokusumo,1989).

Terkait dengan keanekaragaman hayati dari 40.000 spesies tumbuhan dunia, diperkirakan 30.000 spesies tumbuh di kepulauan Indonesia. Selain itu di Indonesia diperkirakan ada 9.600 spesies tanaman yang telah dimanfaatkan oleh 400 ragam etnis untuk pemeliharaan kesehatan maupun pengobatan berbagai macam penyakit. Pewarisan pengetahuan tradisional tentang tumbuhan obat yang sebagian besar dilakukan secara lisan, sehingga baru 300 spesies tanaman yang digunakan sebagai bahan obat oleh industri obat tradisional, 38 produk tanaman obat yang terdaftar sebagai obat herbal terstandar dan 6 produk sebagai fitofarmaka. Menyadari hal tersebut di atas, Pemerintah Indonesia menetapkan pentingnya upaya peningkatan pemanfaatan sumberdaya alam di bidang obat tradisional, diantaranya melalui penyediaan data base yang terkini dan lengkap (Guswan W et al, 2012).

Kajian etnofarmasi merupakan pendekatan secara ilmiah yang dapat membantu dalam menggali pengetahuan suku lokal terhadap resep tradisional berkhasiat obat. Suku Dondo di Sulawesi Tengah tepatnya berada di Kecamatan Dondo Kabupaten Tolitoli. Suku ini telah lama lahir dan menetap di Kecamatan Dondo. Terkait dengan pengobatan, suku Dondo masih mempercayakan dan memanfaatkan tumbuh-tumbuhan sebagai obat.

Penelitian ini bertujuan untuk melakukan inventarisasi, mengetahui cara penggunaan dan bagian tumbuhan yang dimanfaatkan sebagai obat dan diharapkan dapat memberikan sumbangsih informasi terhadap instansi yang terkait mengenai data tumbuhan obat yang dimanfaatkan oleh suku Dondo yang selanjutnya dapat dikembangkan untuk penemuan obat baru.

\section{METODE PENELITIAN Waktu dan Tempat Penelitian}

Penelitian ini dilaksanakan pada bulan Maret sampai Juni 2015, di desa Ogogili, Malomba, Ogogasang Kecamatan Dondo Kabupaten Tolitoli Sulawesi Tengah.

\section{Alat dan Bahan}

Alat yang digunakan dalam penelitian ini antara lain kamera, alat tulis, lakban, karung, kantongan, lembar kuesioner, dan alat pemotong tumbuhan. Adapun bahan yang digunakan yaitu label tempel, alkohol, koran, dan tumbuh-tumbuhan sebagai obat yang ditemukan di lapangan saat melakukan penelitian.

\section{Prosedur Penelitian}

Jenis penelitian ini adalah penelitian deskriptif yang dilakukan pada masyarakat suku Dondo Kecamatan Dondo Kabupaten Tolitoli Sulawesi Tengah.

a. Menentukan Sampel 
Sebelum menentukan sampel, terlebih dahulu peneliti menemui key-informan atau pemangku adat dari suku Dondo dengan maksud meminta izin agar peneliti mendapatkan informasi mengenai pengobatan tradisional dari tumbuh-tumbuhan yang dimanfaatkan sebagai obat oleh suku Dondo. Selanjutnya, sampel dipilih berdasarkan teknik pengambilan sampel yakni (snowball sampling). Dalam penentuan sampel, pertamatama dipilih satu orang sampel (sandro suku Dondo), karena belum lengkap data yang diberikan oleh sandro pertama, maka peneliti mencari sandro lain berdasarkan informasi masyarakat yang dipandang lebih tahu dalam melakukan pengobatan tradisional dan dapat melengkapi data yang diberikan oleh sampel sebelumnnya (Sugiyono, 2007).

b. Wawancara Informan (Sampel)

Wawancara terhadap informan dilakukan dengan teknik open-ended interview, dengan menggunakan media angket kuesioner dan disertai dokumentasi yang mendukung keabsahan dari wawancara informan. Lembar kuesioner digunakan sebagai acuan dalam melakukan pertanyaan terhadap informan. Dari studi lapangan yang dilakukan, para informan ditanya tentang tumbuhan yang dimanfaatkan sebagai obat berdasarkan nama lokal, organ yang digunakan dan cara penggunaanya dalam menyembuhkan suatu penyakit.

c. Pengumpulan Spesimen

Pengumpulan spesimen diambil langsung dari lokasi tumbuhnya dengan dibantu informan atau masyarakat suku Dondo yang mengetahui tumbuhan obat yang dimaksud. Setelah itu spesimen dikoleksi, didokumentasi dan seluruh dokumen yang diambil, diidentifikasi lebih lanjut.

\section{Identifikasi Spesimen}

Identifikasi spesimen dilakukan di UPT Sumber Daya Hayati Sulawesi, untuk mengetahui nama ilmiah dan familia tumbuhan berkhasiat obat yang digunakan oleh suku Dondo Kecamatan Dondo Kabupaten Tolitoli Sulawesi Tengah.

\section{HASIL DAN PEMBAHASAN}

Tanaman obat adalah tanaman yang salah satu, beberapa, atau seluruh bagian tanaman tersebut mengandung zat atau bahan aktif yang berkhasiat bagi kesehatan (Rahardi, 1996).

Hasil identifikasi spesimen yang dilakukan di UPT Sumber Daya Hayati Sulawesi Universitas Tadulako diketahui bahwa jumlah tumbuhan obat yang dimanfaatkan oleh suku Dondo yaitu 56 spesies tumbuhan obat yang terdiri dari 32 jenis familia. Suku Dondo memanfaatkan tumbuhan obat tersebut dari beberapa bagian organ tumbuhan antara lain daun, tangkai daun, batang, kulit batang, bunga, buah, biji, rimpang, umbi, dan herba dengan cara pengolahannya direbus, ditumbuk, disangrai, dibakar, diperas, diseduh dan cara penggunaannya antara lain diminum, dimakan, dikunyah, dihirup uapnya, dioles, ditempelkan/dikompreskan, dipakai mandi, diikatkan, diteteskan, dan digosok di tempat yang sakit. Masyarakat suku Dondo setiap melakukan pengobatan tradisional menggunakan tumbuhan obat disiringi dengan mantra-mantra, salawat kepada nabi atau juga bacaan Al-Qur'an.

Secara etnografi masyarakat Indonesia terdiri dari beratus suku yang masing-masing mempunyai kebudayaan yang berbeda-beda dan pengetahuan lokal tradisional dalam memanfaatkan bahan obat. Pengetahuan obat ini spesifik bagi setiap etnis, sesuai dengan kondisi lingkungan tempat tinggal masing-masing suku atau etnis (Muktiningsih et al., 2001). 
Tabel 1. Familia, Spesies, Khasiat, dan Organ Tumbuhan Obat yang Digunakan Oleh Masyarakat Suku Dondo Kecamatan Dondo Kabupaten Tolitoli, Provinsi Sulawesi Tengah.

\begin{tabular}{|c|c|c|c|}
\hline Familia & Nama spesies / Nama Lokal & $\begin{array}{c}\text { Organ tumbuhan } \\
\text { yang digunakan }\end{array}$ & Penyakit yang Diobati \\
\hline \multirow[t]{8}{*}{ Euphorbiaceae } & Euphorbia heterophylla L. (Kate Mas) & Daun & Gondok \\
\hline & Jatropha gossypiifolia L. (Jarak Merah) & Daun & $\begin{array}{l}\text { Diare } \\
\text { Ambeien }\end{array}$ \\
\hline & Jatropha curcas L (Jarak Pagar) & Daun & $\begin{array}{l}\text { Tekanan Darah Tinggi } \\
\text { Sakit Perut } \\
\text { Cacingan } \\
\text { Jerawat }\end{array}$ \\
\hline & Jatropha multifida L. (Yodium) & Tangkai Daun & Luka sayatan benda tajam \\
\hline & Aleurites moluccanus (L.) Willd. (Kemiri) & Daun & $\begin{array}{l}\text { Kombinasi pada } \\
\text { pengobatan tekanan darah } \\
\text { tinggi }\end{array}$ \\
\hline & & Batang & Mata bayi menguning \\
\hline & & Buah & Bisul \\
\hline & $\begin{array}{l}\text { Melanolepis multiglandulosa (Reinw. ex } \\
\text { Blume) Rchb. \& Zoll. (Alum) }\end{array}$ & Daun & Ambeien \\
\hline \multirow[t]{8}{*}{ Zingiberaceae } & Curcuma longa $\mathrm{L}$. (Kunyit) & Rimpang & Penambah stamina \\
\hline & & Daun & Penambah stamina \\
\hline & Alpinia galanga (L.) Willd (Lengkuas) & Rimpang & Panu, kurap \\
\hline & & Daun & $\begin{array}{l}\text { Keram badan setelah } \\
\text { melahirkan }\end{array}$ \\
\hline & $\begin{array}{l}\text { Boesenbergia rotunda (L.) Mansf. (Temu } \\
\text { kunci) }\end{array}$ & Batang & Panas dalam \\
\hline & Zingiber officinale Roscoe (Jahe) & Rimpang & Bisul \\
\hline & & Rimpang & $\begin{array}{l}\text { Melancarkan darah setelah } \\
\text { melahirkan }\end{array}$ \\
\hline & $\begin{array}{l}\text { Chromolaena odorata (L.) R.M.King \& H.Rob. } \\
\text { (Ombuno) }\end{array}$ & Daun & Panas dalam \\
\hline \multirow[t]{6}{*}{ Asteraceae } & $\begin{array}{l}\text { Blumea balsamifera (L.) DC. (Tembakau } \\
\text { Hutan) }\end{array}$ & Daun & Mimisan \\
\hline & & Daun & Batuk \\
\hline & & Daun & Usus buntu \\
\hline & & Daun & $\begin{array}{l}\text { Darah berbau saat } \\
\text { menstruasi }\end{array}$ \\
\hline & $\begin{array}{l}\text { Conyza sumatrensis (S.F.Blake) Pruski \& } \\
\text { G.Sancho. (Cabi) }\end{array}$ & Daun & Jerawat \\
\hline & $\begin{array}{l}\text { Synedrella nodiflora (L.) Gaertn. (Gletang } \\
\text { warak) }\end{array}$ & Daun & Luka benda tajam \\
\hline \multirow[t]{7}{*}{ Malvaceae } & Hibiscus surattensis L. (Asam susur) & Daun & Penyakit kuning \\
\hline & Hibiscus tilliaceus L. (Waru lengis) & Batang muda & Keracunan \\
\hline & Kleinhovia hospita L. (Timo) & Daun & Diabetes \\
\hline & & Daun & Mimisan \\
\hline & & Daun & Demam \\
\hline & Ceiba pentandra (L.) Gaertn. (Kapuk) & Buah & Mimisan \\
\hline & & Kulit batang & $\begin{array}{l}\text { Kombinasi pada } \\
\text { pengobatan bisul }\end{array}$ \\
\hline \multirow[t]{4}{*}{ Musaceae } & Musa sp. (Pisang emas) & Batang & Keracunan \\
\hline & Musa sp. (Pisang sepatu) & Daun & Penyakit kuning \\
\hline & & Daun & $\begin{array}{l}\text { Keram badan setelah } \\
\text { melahirkan }\end{array}$ \\
\hline & Musa sp. (Pisang tanduk) & Batang & Bisul \\
\hline \multirow[t]{2}{*}{ Cucurbitaceae } & Momordica charantia L. (Paria) & Daun & Bayi muntah-muntah \\
\hline & Cucurbita moschata Duchesne. (Labu) & Bunga & $\begin{array}{l}\text { Kombinasi pada } \\
\text { pengobatan kulit terkupas }\end{array}$ \\
\hline \multirow[t]{3}{*}{ Solanaceae } & Physalis angulata L. (Ciplukan) & Daun & Asma \\
\hline & & Daun & Sakit perut \\
\hline & Capsium annuиm L. (Rica) & Daun & $\begin{array}{l}\text { Kombinasi pada } \\
\text { pengobatan jerawat }\end{array}$ \\
\hline \multirow[t]{2}{*}{ Lamiaceae } & $\begin{array}{l}\text { Plectranthus scutellarioides (L.) R.Br. } \\
\text { (Mariana) }\end{array}$ & Daun & Muntah-muntah \\
\hline & Volkameria inermis L. (Kayu jumaat) & Daun & Penyakit kulit pada bayi \\
\hline
\end{tabular}




\section{Fajrin et al./Galenika Journal of Pharmacy}

\begin{tabular}{|c|c|c|c|}
\hline \multirow[t]{3}{*}{ Rubiaceae } & Neonauclea sp. (Lengkaba) & $\begin{array}{l}\text { Daun } \\
\text { Batang } \\
\text { Daun }\end{array}$ & $\begin{array}{l}\text { Sakit mata } \\
\text { Muntah-muntah } \\
\text { Bengka-bengka badan } \\
\text { setelah melahirkan }\end{array}$ \\
\hline & Morinda citrifolia L. (Mengkudu) & Daun & TBC \\
\hline & & Buah & Penambah stamina \\
\hline \multirow[t]{6}{*}{ Piperaceae } & Piper sp. (Sirih) & Daun & Kanker payudara \\
\hline & & Daun & Darah putih naik ke kepala \\
\hline & & Daun & Keputihan \\
\hline & & Daun & Sakit mata \\
\hline & & Daun & Kulit mengelupas \\
\hline & Piper nigrum L. (Rica jawa) & Buah & $\begin{array}{l}\text { Kombinasi pada } \\
\text { pengobatan melancarkan } \\
\text { darah }\end{array}$ \\
\hline \multirow[t]{3}{*}{ Leguminosae } & Senna alata (L.) Roxb. (Ketepeng cina) & Daun & Panu, kurap \\
\hline & & Daun & Kulit mengelupas \\
\hline & Glycine $\max$ (L.) Merr. (Kedelei) & Biji & $\begin{array}{l}\text { Kombinasi pada } \\
\text { pengobatan usus turun }\end{array}$ \\
\hline \multirow[t]{2}{*}{ Poaceae } & Zea mays L. (Jagung) & Biji & $\begin{array}{l}\text { Kombinasi pada } \\
\text { pengobatan penyakit kulit } \\
\text { pada bayi, dan keram } \\
\text { badan setelah melahirkan. }\end{array}$ \\
\hline & & Buah & Kulit terkupas \\
\hline \multirow[t]{6}{*}{ Arecaceae } & Cocos nucifera L. (Kelapa) & Buah & Keracunan \\
\hline & & Buah & Muntah berak \\
\hline & Areca catechu L. (Pinang) & Biji & Diabetes \\
\hline & & Biji & Luka akibat diabetes \\
\hline & & Buah & Keputihan \\
\hline & & Buah & $\begin{array}{l}\text { Bengka-bengka badan } \\
\text { setelah melahirkan }\end{array}$ \\
\hline Annonaceae & Annona muricata L. (Sirsak) & Daun & Sakit kepala \\
\hline \multirow[t]{2}{*}{ Phyllanthaceae } & Phyllanthus sp. (Meniran) & Herba & Cacingan \\
\hline & & Daun & Sembelit \\
\hline Crassulaceae & $\begin{array}{l}\text { Bryophyllum pinnatum (Lam.) Oken. (Cocor } \\
\text { bebek) }\end{array}$ & Daun & Sakit kepala \\
\hline Costaceae & $\begin{array}{l}\text { Cheilocostus speciosus (J.Koenig) C.D.Specht. } \\
\text { (Pacing tawar) }\end{array}$ & Batang & Sakit mata \\
\hline \multirow[t]{3}{*}{ Melastomataceae } & Melastoma malabathricum L. (Senduduk) & Daun & Diare \\
\hline & & Daun & Panas dalam \\
\hline & & Daun & Sakit perut \\
\hline & Colocasia esculenta (L.) Schott. (Talas) & Tangkai daun & Luka sayatan benda tajam \\
\hline \multirow[t]{2}{*}{ Moraceae } & Ficus septica Burm.f. (Awar-awar) & Daun & Panas dalam \\
\hline & & Daun & $\begin{array}{l}\text { Keram badan setelah } \\
\text { melahirkan }\end{array}$ \\
\hline Loranthaceae & Dendrophthoe pentandra (L.) Miq. (Benalu) & Batang & Usus turun \\
\hline Dennstaedtiaceae & Pteridium sp. (Pakuan) & Daun & Gatal-gatal \\
\hline Pandanaceae & $\begin{array}{l}\text { Pandanus tectorius Parkinson ex Du Roi. } \\
\text { (Pandan tikar) }\end{array}$ & Batang & Keracunan \\
\hline Amaryllidaceae & $\begin{array}{l}\text { Proiphys amboinensis (L.) Herb. (Anggrek } \\
\text { bulan ambon) }\end{array}$ & Umbi & Gondok \\
\hline Moringaceae & Moringa oleifera Lam. (Kelor) & Daun & Mata tinggi \\
\hline \multirow[t]{2}{*}{ Oxalidaceae } & Averrhoa bilimbi L. (Belimbing wuluh) & Daun & Tekanan darah tinggi \\
\hline & & Daun & Darah putih naik ke kepala \\
\hline \multirow[t]{2}{*}{ Acanthaceae } & $\begin{array}{l}\text { Andrographis paniculata (Burm.f.) Nees } \\
\text { (Sambiloto) }\end{array}$ & Batang & Asma \\
\hline & & Batang & Penambah stamina \\
\hline Anacardiaceae & $\begin{array}{l}\text { Lannea coromandelica (Houtt.) Merr. (Kayu } \\
\text { jawa) }\end{array}$ & Batang & Maag \\
\hline Rutaceae & $\begin{array}{l}\text { Citrus aurantiifolia (Christm.) Swingle. (Jeruk } \\
\text { nipis) }\end{array}$ & Buah & Batuk \\
\hline \multirow[t]{5}{*}{ Verbenaceae } & Lantana camara L. (Tembelekan) & Daun & Kanker payudara \\
\hline & & Daun & Asma \\
\hline & & Daun & Usus buntu \\
\hline & & Daun & Muntah berak \\
\hline & & Daun & Muntah-muntah \\
\hline Myrtaceae & Psidium guajava L. (Jambu biji) & Daun & Sakit perut \\
\hline Vitaceae & Cayratia trifolia $($ L.) Domin (Galing) & Daun & Sakit kepala \\
\hline
\end{tabular}


Tabel.2. Persentase Organ Tumbuhan Obat yang Digunakan Oleh Masyarakat Suku Dondo Kecamatan Dondo Kabupaten Tolitoli, Provinsi Sulawesi Tengah.

\begin{tabular}{lc}
\hline $\begin{array}{l}\text { Bagian Tumbuhan } \\
\text { Yang digunakan }\end{array}$ & Persentase \\
\hline Daun & $62 \%$ \\
Tangkai Daun & $2 \%$ \\
Batang & $14 \%$ \\
Buah & $10 \%$ \\
Rimpang & $4 \%$ \\
\hline
\end{tabular}

\begin{tabular}{lc}
\hline \multicolumn{1}{c}{$\begin{array}{c}\text { Bagian Tumbuhan } \\
\text { Yang digunakan }\end{array}$} & Persentase \\
\hline Biji & $4 \%$ \\
Kulit Batang & $1 \%$ \\
Bunga & $1 \%$ \\
Umbi & $1 \%$ \\
Herba & $1 \%$ \\
\hline
\end{tabular}

Berikut beberapa contoh cara pengolahan tumbuhan obat oleh suku Dondo Kecamatan Dondo Kabupaten Tolitoli

1. Tekanan darah tinggi diobati dengan menggunakan daun Jarak pagar (Jatropha curcas L.) sebanyak 3 pucuk dan daun Kemiri remaja (Aleurites moluccanus (L.) Willd.) sebanyak 3 pucuk, direbus sampai mendidih menggunakan air sebanyak 3 gelas atau $500 \mathrm{ml}$, disaring dan kemudian airnya diminum sampai sembuh pada waktu pagi, siang dan malam.

2. Lemas setelah melahirkan diobati dengan mengambil bagian batang Galing (Cayratia trifolia (L.) Domin) secukupnya, lalu diikatkan pada bagian-bagian yang sakit.

3. Ambeien diobati dengan menggunakan 3 pucuk daun Jarak merah (Jatropha gossypiifolia L.), diseduh dengan air panas, diamkan hingga hangat, lalu diminum 1 gelas pada waktu pagi dan malam selama 3 hari.

4. Susah buang air besar atau sembelit diobati dengan cara mengambil daun Kate mas (Euphorbia heterophylla L.) dan tambahkan garam secukupnya, direbus dengan air sebanyak $1 / 2$ liter, disaring, lalu airnya diminum pada waktu pagi dan malam.

5. Mimisan atau apitaksis diobati dengan buah Kapuk (Ceiba pentandra (L.) Gaertn.) muda, dibakar lalu asapnya dihirup sampai dengan darah berhenti keluar.
6. Keracunan dapat diobati dengan Pandan tikar (Pandanus tectorius Parkinson ex Du Roi.) yang muda dikupas lalu diambil kelapa tua $1 / 2$ telapak tangan keduanya diparut. Selanjutnya, dicampur dengan air, diperas, lalu hasil perasan diminum pada waktu pagi dan malam.

Jumlah inventarisasi tumbuhan obat yang dimanfaatkan oleh suku Dondo di kecamatan Dondo kabupaten Tolitoli diketahui 56 spesies tumbuhan obat yang terdiri dari 32 jenis familia, dan organ tumbuhan yang digunakan antara lain daun, tangkai daun, batang, kulit batang, bunga, buah, biji, rimpang, umbi, dan herba. Adapun cara pengolahannya antara lain direbus, ditumbuk, disangrai, dibakar, diperas, diseduh dan cara penggunaannya diminum, dimakan, dikunyah, dihirup uapnya, dioles, ditempelkan/ dikompreskan, dipakai mandi, diikatkan, diteteskan, dan digosok di tempat yang sakit.

Selanjutnya, perlu dilakukan budidaya dan analisis lebih lanjut mengenai komposisi kandungan kimia dari berbagai spesies tumbuhan obat yang digunakan oleh masyarakat suku Dondo, guna memperoleh temuan obat baru yang potensial dalam menyembuhkan suatu penyakit.

\section{DAFTAR PUSTAKA}

Muktiningsih, S. R., Syahrul, M., Harsana, I. W., Budhi, M., dan Panjaitan, P. 
(2001). Review Tanaman Obat Yang Digunakan Oleh Pengobat Tradisional Di Sumatra Utara, Sumatra Selatan. Bali dan Sulawesi Selatan. Media Litbang Kesehatan.

Rahardi, F. (1996). Membuat Kebun Tanaman Obat. Puspa Swara. Jakarta.

Sosrokusumo, P. (1989). Pelayanan pengobatan tradisional di bidang kesehatan jiwa. Dalam: Salan, R., Boedihartono, P. Pakan, Z.S. Kuntjoro, dan I.B.I. Gotama (ed.). (1988). Lokakarya tentang Penelitian Praktek Pengobatan
Tradisonal. Badan Penelitian dan Pengembangan Kesehatan, Deparetem Kesehatan Republik Indonesia. Ciawi. 14-17.

Sugiyono. (2007). Memahami Penelitian Kualitatif. Alfabeta. Bandung.

Wiwaha, G., Jasaputra, S.N.B.D.K., Rohmawaty, E., Yunivita, KD. V., \& Muchtar, E. (2012). Tinjauan Etnofarmakologi Tumbuhan Obat/Ramuan Obat Tradisional untuk Pengobatan Dislipidemi yang Menjadi Kearifan Lokal Di Provinsi Jawa Barat. Jurnal Medika Planta Vol. 2 No. 1., 64. 